\title{
Early diagnosis of HIV-I infection in Cambodian infants
} Sopheak Ngin*1, Sim Leang Kruy ${ }^{2}$, Olivier Segeral ${ }^{3,7}$, Viseth Srey Horm ${ }^{1}$, Ly Meng Ek², Im Sethikar², Vara Ouk²,3, Vibol Ung', Olivier Marcy, ${ }^{4,5}$, Christine Rouzioux ${ }^{6}$, Jean François Delfraissy ${ }^{3,7}$ and Eric Nerrienet ${ }^{1}$

\author{
Address: ${ }^{1}$ HIV/Hepatitis Laboratory, Institut Pasteur du Cambodge, Phnom Penh, Cambodia, ${ }^{2}$ Calmette Hospital, Phnom Penh, Cambodia, \\ ${ }^{3}$ ESTHER/Calmette Hospital, Phnom Penh, Cambodia, ${ }^{4}$ National Paediatric Hospital, Phnom Penh, Cambodia, ${ }^{5}$ French Red Cross, France, \\ ${ }^{6}$ Laboratoire de virologie, EA 3620, Université Paris-Descarte, CHU Necker-Enfants Malades, Paris, France and ${ }^{7}$ Clinical Immunology Department, \\ CHU Bicêtre, Kremlin Bicêtre, Paris, France \\ * Corresponding author
}

from Fourth Dominique Dormont International Conference. Host-Pathogen Interactions in Chronic Infections

Paris, France. 13-15 December 2007

Published: 9 April 2008

Retrovirology 2008, 5(SuppI I):P22 doi:10.1 186/1742-4690-5-SI-P22

This abstract is available from: http://www.retrovirology.com/content/5/SI/P22

(c) 2008 Ngin et al.; licensee BioMed Central Ltd.

\section{Objective}

In Cambodia, national programs to prevent mother-tochild transmission (MTCT) of HIV, scaled up since 2001, were hampered by lack of access to HIV early diagnosis in infancy. A low cost strategy to assess HIV-RNA viral load, was implemented in 2005 and applied to the early diagnosis in infants. Our objectives were i) to generate information on the early diagnosis of HIV infection in Cambodia, and ii) to estimate the in utero and perinatal MTCT rates of HIV-1 among mothers delivering at Calmette Hospital, Phnom Penh.

\section{Methods}

Detection of HIV-RNA in infants was determined using the ANRS second-generation (G2) real-time RT-PCR test.

\section{Results}

i) Between May 2005 and February 2007, 755 plasma samples from children (mean age: 5.5 months [1-18]), born from HIV-infected mothers were screened for HIV infection. Samples originated from Phnom Penh (57.8\%) and from 5 provinces (42.2\%). Sex Ratio F/M was 0.97 . Data showed that $134 / 755$ (17.7\%) samples were HIVRNA positive (mean viral load: $6.4 \log _{10}$ [3.9-8.6]. ii) During the study period, 157 HIV-infected pregnant women (mean age: 27, IQR [25-31]) attended antenatal care and delivered at Calmette Hospital. Among those, 77 (49\%) on HAART delivered 77 babies of whom 2 were
HIV-RNA positive (MTCT: 2.6\%). Twenty-eight (18.1\%), not eligible for HAART, received AZT then sdNVP during labour: 3/28 (10.7\%) babies were HIV-RNA positive. Forty-one $(26 \%)$ received only sdNVP during labour because of HIV late testing: 6 infants (14.6\%) were diagnosed HIV-RNA positive. Finally, 11 mothers did not receive any prophylaxis: 2 infants (18.1\%) were HIV-RNA positive.

\section{Conclusions}

This study confirms the usefulness of the HIV RNA ANRS (G2) real-time RT-PCR test to diagnose early HIV-1 infection in infancy and to monitor PMTCT programs. This study also highlights the urgent need to expend the early diagnosis at the national level to improve medical care of HIV infected Cambodian children and to expand HAART access for women during pregnancy to reduce MTCT. 